\title{
Proceeding
}

Supplementary Issue: Autumn Conferences of Sports Science. Costa Blanca Sports Science Events, 2-3 November 2018.

Alicante, Spain

\section{Powerglove: Genesis of a wearable technology aimed at studying volleyball service}

\author{
PIO ALFREDO DI TORE ${ }^{1} \triangleleft$, GAETANO RAIOLA ${ }^{2}$ \\ 1 University of Foggia, Italy \\ 2University of Salerno, Italy
}

\begin{abstract}
The spread, in sport, of technologies able to detect and organize in real time a wide range of data related to the athlete and the context (tracker, gps, gyroscopes, accelerometers, bio-sensors embedded in smartphones or available as wearable devices) offers a great opportunity to collect performance data, allowing objective, accurate and non-invasive physical activity monitoring. In particular, this type of detection allows to avoid all the interferences connected to the laboratory settings. Wearable devices using textiles with embedded physiological sensors are used in various applications involving monitoring, control and learning» (Helmer et al., 2010). In sport, wearable technologies allow detections that do not alter the "natural" scenario of the performance. This work presents the design and development of a wearable device for the collection of data relating to a fundamental of volleyball: the service. The device consists of a glove, wearable by the athlete, equipped with various ultra-thin sensors (such as not to affect performance). The sensors are operated by an Arduino Nano microcontroller, worn at the forearm level by an arm band. The basic sensor is a flexible and ultra-thin TekScan pressure sensor $(<0.1 \mathrm{~mm})$, able to detect the pressure exerted by the hand on the ball in a range between 0 and $100 \mathrm{~kg}$ with an accuracy of $100 \mathrm{~g}$ and a sampling frequency of $100 \mathrm{~Hz}$. Collected data are processed by a specially developed support software that provides elementary statistics and specific graphical representations and can be exported in the most common formats. Key words: Wearable devices; Performance analysis; Data recruiting.
\end{abstract}

\section{Cite this article as:}

Di Tore, P.A., \& Raiola, G. (2019). Powerglove: Genesis of a wearable technology aimed at studying volleyball service. Journal of Human Sport and Exercise, 14(1proc), S77-S83. doi:https://doi.org/10.14198/ihse.2019.14.Proc1.09

Corresponding author. University of Foggia, Italy.

E-mail: alfredo.ditore@gmail.com

Supplementary Issue: Autumn Conferences of Sports Science. Costa Blanca Sports Science Events, 2-3 November 2018. Alicante, Spain.

JOURNAL OF HUMAN SPORT \& EXERCISE ISSN 1988-5202

(C) Faculty of Education. University of Alicante.

doi:10.14198/jhse.2019.14.Proc1.09 


\section{INTRODUCTION}

In sport, the need to detect and organize in real time a wide range of data relative to the athlete and the context is becoming widespread. Contemporary technology (trackers, gps, gyroscopes, accelerometers, biosensors embedded in smartphones or available as wearable devices) offers a great opportunity to collect performance data, but objective, accurate and non-invasive monitoring of physical activity is not always possible. In particular, it is necessary to implement data recruiting methods and tools that avoid all the interferences connected to the laboratory settings: «An athlete studied within laboratorial conditions might perform quite differently from on the field» (Armstrong, 2007). Helmer et al. explicitly connect the ability to capture performance data with the development of interactive models for coaching:« wearable devices extend the body in a real and virtual manner. The flow of information and stimuli from real - to - virtual, and virtual -to - real enable experiences to be shared across time and space. Wearable devices using textiles with embedded physiological sensors are used in various applications involving monitoring, control and learning» (Helmer et al., 2010).

Wearable technologies allow such data to be recruited without altering the "natural" performance scenario (Author1, 2015; Author1, Author2, \& D'Isanto, 2018); these technologies must undergo such design and development as to follow a strict protocol to ensure that the information obtained is objective, reliable, accurate and valid (Ferrara \& Author1, 2018).

According to literature, the performance analysis has a significant value in the process of improving the knowledge of the parameters that affect the performance itself (Forte \& Altavilla, 2018; Author2, Altavilla, De Luca, \& Author1, 2016).

In team sports, such as volleyball, this information allows you to become more familiar with the dynamic system involved during matches. A review in the literature revealed that, in volleyball, despite it being a sport heavily affected by the presence of technologies during performance and training (think of the spread of software for video analysis or for coaching), there is no significant presence of wearable measuring instruments. The present work concerns the design of an instrument (PowerGlove) able to measure the pressure exerted by the palm of the hand on the ball during the execution of the serve.

\section{SUMMARY}

The device illustrated below allows to overcome the known technique and to obtain, by means of an objective, accurate and non-invasive physical activity monitoring, the performance data mentioned.

The device consists of a glove worn by the athlete and equipped with various ultra-thin sensors that do not affect the performance.

The device is equipped with sensors managed by a control unit that can be worn at the forearm level by means of an "arm band" support that does not interfere with performance. Even the small dimensions of the control unit are such as to achieve the same effect.

The control unit contains a series of essential elements for processing and broadcasting the data detected by the sensors. 
The sensor is flexible and ultra-thin, able to detect the pressure exerted by the athlete's hand on the ball in a range of known values and with measurement accuracy also known. The sampling frequency of the detected data is pre-established.

The collected data are processed by a support software developed ad hoc that provides the elementary statistics and specific graphical representations. The data thus obtained can be exported in the most common formats.

The use of the device allows to obtain considerable advantages, with respect to the known art, among which:

- $\quad$ collect information about players in their natural context without interfering in their behaviour. This allows to establish relationships between the execution mode and the temporal and spatial aspects of the execution with the effect of the actions in the game.

- $\quad$ provide analysts, coaches and athletes with an objective fact far from simple human perception.

\section{MATERIALS AND METHODOLOGY}

The prototype created is a wearable device for the collection of data related to two fundamentals of volleyball: the serve and the smash.

Basic elements of the device are:

- a glove,

- $\quad$ ultra-thin sensors managed by a micro controller

In which the overall arrangement is such that the sensors connected to the glove detect data relating to the pressure exerted by the hand on the ball during serve or smash.

\section{Formats}

The device consists of a glove, wearable by the athlete, equipped with various ultra-thin sensors (such as not to affect performance). The sensors are operated by an Arduino Nano microcontroller, worn at the forearm level by an arm band. The basic sensor is a flexible and ultra-thin TekScan pressure sensor $(<0.1 \mathrm{~mm})$, able to detect the pressure exerted by the hand on the ball in a range between 0 and $100 \mathrm{~kg}$ with an accuracy of $100 \mathrm{~g}$ and a sampling frequency of $100 \mathrm{~Hz}$.

Collected data are processed by a specially developed support software that provides elementary statistics and specific graphical representations and can be exported in the most common formats.

The tool collects information on: a) force, b) surface, c) impact time d) direction. The tool can be used for research and coaching purposes.

The control unit is equipped with a small enclosure, $62 \mathrm{~mm}$ in length, $19 \mathrm{~mm}$ in height and $42 \mathrm{~mm}$ in depth. These dimensions make it possible to place the unit easily on the athlete's forearm without interfering with the performance. The casing is printed by $3 \mathrm{D}$ printing. 
The control unit contains within its envelope a series of elements essential for the detection, processing and sending of data detected by the sensors.

- a Bluetooth module

- $\quad$ an Arduino nano micro controller;

- $\quad$ a printed circuit board specially designed and manufactured

- $\quad$ a 100 mah battery charger circuit

- $\quad$ a single cell lithium battery and 500 mah and $3.7 \mathrm{~V}$

- $\quad$ an electric step up from $3.7 \mathrm{~V}$ to $5 \mathrm{~V}$

The device is connected to:

- 2 Tekscan sensors (FlexiForce 445N).

- 1 Tekscan sensor (FlexiForce A401 Sensor)

Tekscan sensors were the most accurate among those analysed. Typically used for industrial or biomedical applications, the sensors appear to have a detection error of less than $1 \%$ compared to the range used. Each sensor can be calibrated with respect to a specific weight range (For the $445 \mathrm{~N}$ sensor the range varies between 0 and $453.592 \mathrm{~kg}$, for the sensor A401 the range varies between 0 and $3175.147 \mathrm{~kg}$ ). The sensors can be calibrated by changing the input or output resistance, as shown in the wiring diagram in figure 4 . In the case shown here, the sensors have all been calibrated to measure the range 0-100 kg.

The acquired data are transmitted via Bluetooth to Windows and Android operating systems and the transmission frequency is $50 \mathrm{~Hz}$. Sensor changes are stored in memory in the time intervals between acquisition and sending to the master device.

The device has an autonomy of about 3 hours and a charging time of 2 hours.

\section{RESULTS}

The prototype created, currently being tested during volleyball matches, is illustrated in the attached figures:

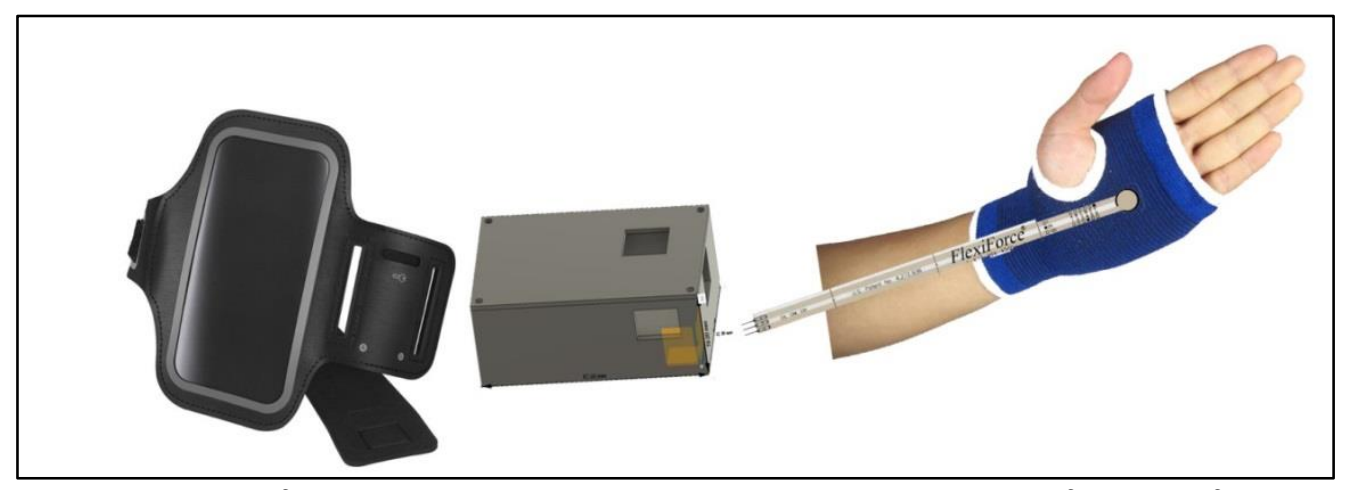

Figure 1. A schematization of the device and its components as arranged on the forearm of an athlete during performance 


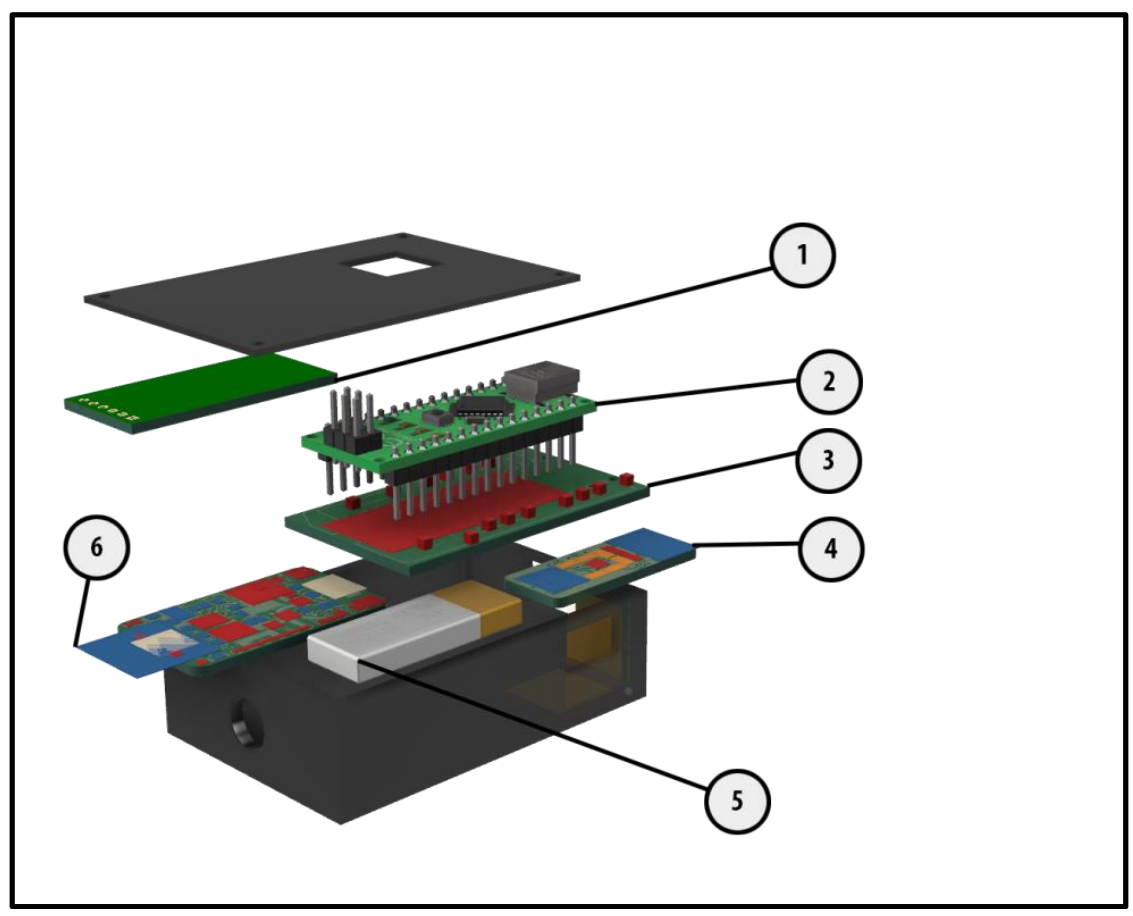

Figure 2. An exploded view of the control unit with its constituent elements

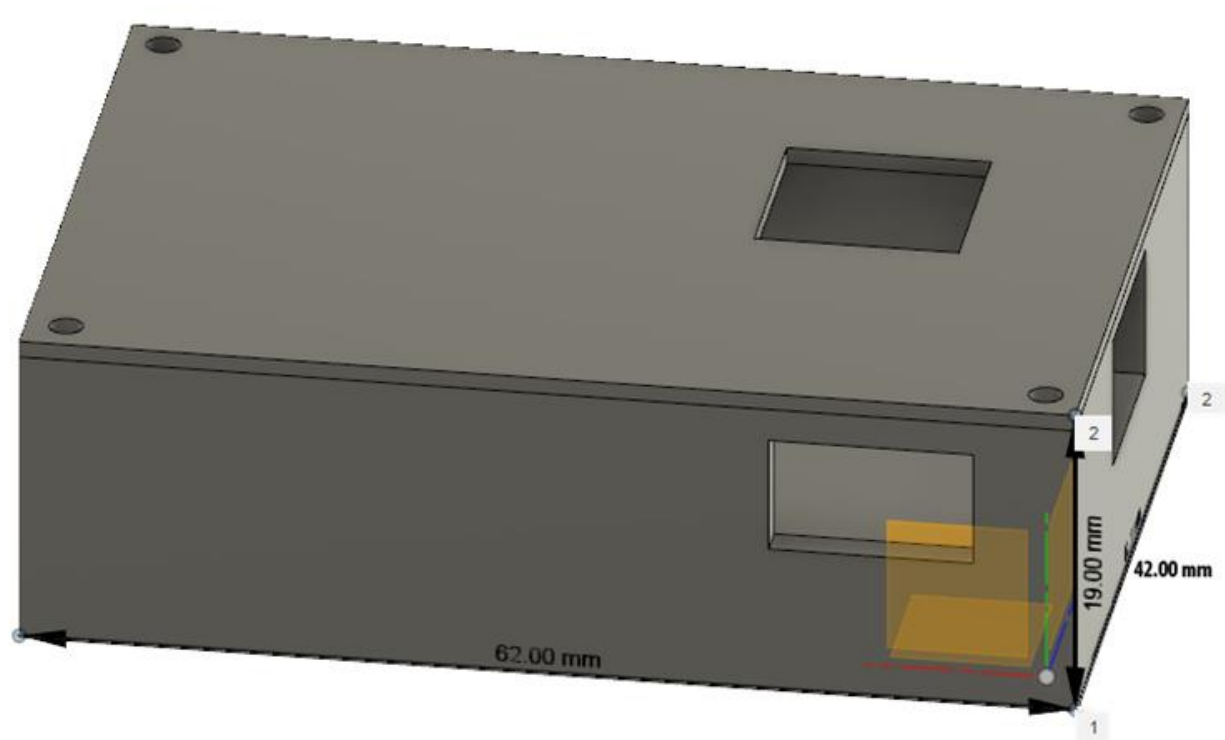

Figure 3. The housing of the control unit highlighting the three dimensions $(L, H, P)$ 


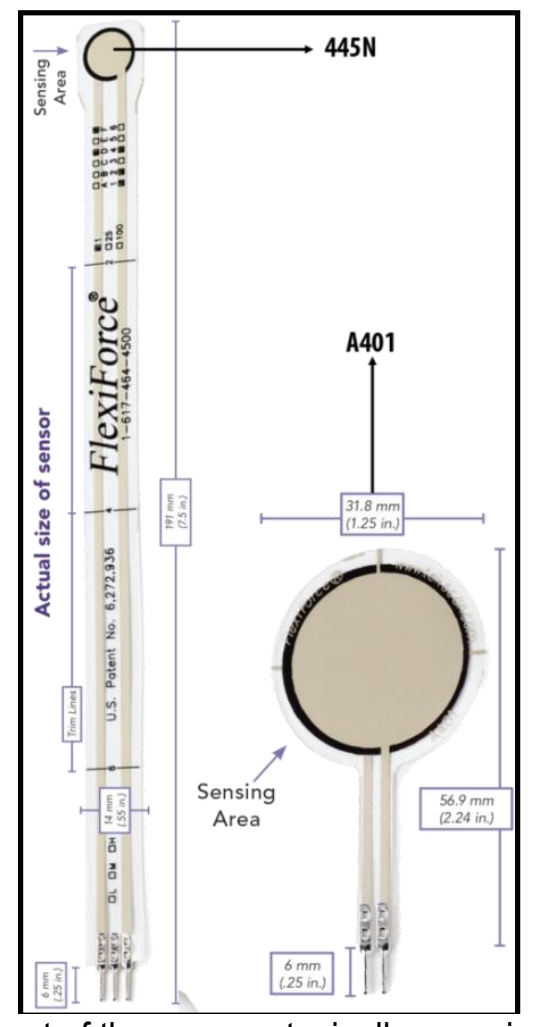

Figure 4. A data sheet of the sensors typically associated with the device

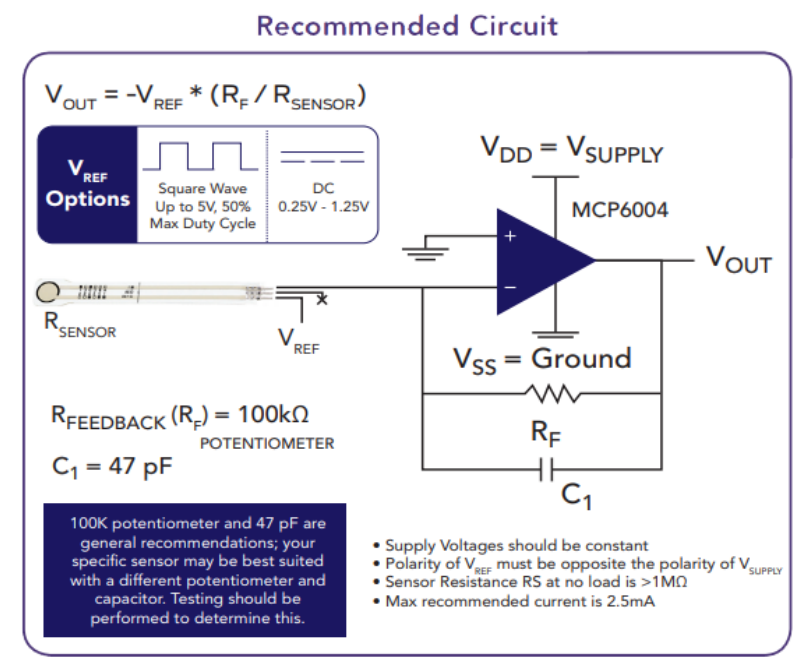

\begin{tabular}{l|cc}
\cline { 2 - 3 } & \multicolumn{1}{c}{ Typical Performance } & Evaluation Conditions \\
\hline Linearity (Error) & $< \pm 3 \%$ of full scale & Line drawn from 0 to $50 \%$ load \\
\hline Repeatability & $< \pm 2.5 \%$ & Conditioned sensor, $80 \%$ of full force applied \\
\hline Hysteresis & $<4.5 \%$ of full scale & Conditioned sensor, $80 \%$ of full force applied \\
\hline Drift & $<5 \%$ per logarithmic time scale & Constant load of $111 \mathrm{~N}(25 \mathrm{lb})$ \\
\hline Response Time & $<5 \mu \mathrm{sec}$ & Impact load, output recorded on oscilloscope \\
\hline Operating Temperature & $-40^{\circ} \mathrm{C}-60^{\circ} \mathrm{C}\left(-40^{\circ} \mathrm{F}-140^{\circ} \mathrm{F}\right)$ & Convection and conduction heat sources \\
\hline Acceptance Criteria & $\pm 40 \%$ sensor-to-sensor variation & \\
\cline { 2 - 3 }
\end{tabular}

Figure 5. An electrical diagram of the sensors associated with the device 


\section{CONCLUSIONS}

Future research will be aimed at identifying the most efficient configuration (in terms of bit-depth and frequency of acquisition and number of usable sensors). At present, a version 2.0 of the device is being implemented, equipped with 6 sensors ( 5 sensors $445 \mathrm{~N}$ and 1 sensor A401) aimed at obtaining a mapping of the distribution of weight on the hand. The 2.0 version will also be equipped with two IMUs (Inertial Motion Units - 10Degree Of Freedom) consisting of gyroscope, accelerometer and compass. The purpose of the insertion of the IMU is to evaluate the orientation of the arm and the hand during the recording.

\section{REFERENCES}

Armstrong, S. (2007). Wireless connectivity for health and sports monitoring: a review. British journal of sports medicine, 41(5), 285-289. https://doi.org/10.1136/bjsm.2006.030015

Di Tore, P. A. (2015). Situation awareness and complexity: the role of wearable technologies in sports science. JHSE, 10(Proc1), s500-s5006. https://doi.org/10.14198//hse.2015.10.Proc1.44

Di Tore, P. A., Raiola, G., \& D'Isanto, T. (2018). Situation awareness in sports science: Beyond the cognitive paradigm. Sport Science, 11(1), 5.

Ferrara, F., \& Di Tore, P. A. (2018). Preliminary work on the testing of power glove applied to volleyball. Journal of Physical Education and Sport (JPES), 18(supplement issue 5), 5.

Forte, D., \& Altavilla, G. (2018). Preliminary correlation between anthropometric and performance data in volleyball about the transition period. Journal of Physical Education and Sport (JPES), 18(supplement issue 5), 5 .

Helmer, R., Mestrovic, M., Taylor, K., Philpot, B., Wilde, D., \& Farrow, D. (2010). Physiological tracking, wearable interactive systems and human performance. Paper presented at the Proc. of the 20th Intl. Conf. on Artificial Reality and Telexistence.

Raiola, G., Altavilla, G., De Luca, C., \& Di Tore, P. A. (2016). Analysis on some aspects of the service in volleyball. Sport Science, 9(1), 74-77.

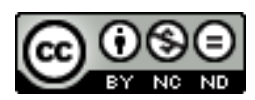

This work is licensed under a Attribution-NonCommercial-NoDerivatives 4.0 International (CC BY-NC-ND 4.0). 